\title{
Bioglass: A New Era in Modern Dentistry
}

\author{
Shruti Singh ${ }^{1} \quad$ Amit Patil $^{1}$ Sheetal Mali ${ }^{1}$ Himmat Jaiswal ${ }^{1}$ \\ ${ }^{1}$ Department of Conservative and Endodontics, Bharati Vidyapeeth \\ (Deemed to be University) Dental College and Hospital, Navi \\ Address for correspondence Shruti Singh, BDS, Bharati Vidyapeeth \\ Mumbai, Maharashtra, India \\ (Deemed to be University) Dental College, Navi Mumbai - 400614, \\ Maharashtra, India (e-mail: shrutissingh.05@gmail.com).
}

Eur J Gen Dent 2022;11:1-6.

\begin{abstract}
Keywords

- Bioglass

- hydroxyapatite

- broad-spectrum antimicrobial

- bioactive glass

- sol-gel technique

The function of biomaterials has been to replace infected or injured tissues. The first used biomaterials were bioinert, thus minimizing formation of scar tissue at the interface with host tissues. Bioglass was discovered in 1969. Larry Hench developed Bioglass 45S5, which was the earliest synthetic substance that was bonded chemically with bone. In recent researches it has appeared that Bioglass bonds with bone more readily than other bioceramics; it also indicated that the osteogenic properties are due to stimulation of osteoprogenitor cells by the dissolution products formed from Bioglass. Bioglass is chemically calcium sodium phosphosilicate, which is capable of forming an active chemical bond with the tissues. Bioglass is particularly biocompatible which, when placed in body cavity or on reacting with body stimulating factors, induces hydroxyapatite formation. This paper reviews Bioglass as a material of modern dentistry and its various applications in modern dentistry. It also discusses its composition, methods of preparation, and mechanism of action, along with its advantages and disadvantages.
\end{abstract}

\section{Introduction}

Like wheels of time, dentistry too keeps evolving and innovating; one of such innovation is Bioglass, developed by Hench in 1969. It comprises of calcium sodium phosphosilicate. Bioglass precipitates hydroxyapatite crystal in aqueous solution, which has ability to bond with soft and hard tissues of the body without rejection. The bioactivity of Bioglass is due its reactions with tissue fluids, which initiates hydroxyapatite crystal formation. The properties of bioactivity along with biocompatibility paved way for Bioglass into modern dentistry for various purposes such as for repair of voids and defects of facial bone, remodeling of dentoalveolar complex, etc. ${ }^{1}$

\section{History}

Bioglass was developed by Professor Larry Hench, of University of Florida, in 1969. The idea of developing a material that could bond to bone struck him in a conversation with a US army colonel who had just returned from war. The colonel suggested for a material to be flourished that would be compatible with human body, since implants then available were made of metals or polymers that were bioinert and caused fibrous encapsulation in preference to a stable bond with tissue. ${ }^{1}$

The main discovery was of a glass with the composition $46.1 \mathrm{~mol} \%$ silicon dioxide, $24.4 \mathrm{~mol} \%$ sodium oxide $\left(\mathrm{Na}_{2} \mathrm{O}\right)$, $26.9 \mathrm{~mol} \%$ calcium oxide $(\mathrm{CaO})$, and $2.6 \mathrm{~mol} \%$ phosphorus pentoxide $\left(\mathrm{P}_{2} \mathrm{O}_{5}\right)$, later termed Bioglass $45 \mathrm{~S} 5$, which forms
DOI https://doi.org/ $10.1055 / \mathrm{s}-0042-1742356$. ISSN 2320-4753.
(C) 2022. The Author(s).

This is an open access article published by Thieme under the terms of the Creative Commons Attribution License, permitting unrestricted use, distribution, and reproduction so long as the original work is properly cited. (https://creativecommons.org/licenses/by/4.0/)

Thieme Medical and Scientific Publishers Pvt. Ltd., A-12, 2nd Floor, Sector 2, Noida-201301 UP, India 
2 Bioglass: A New Era in Modern Dentistry Singh et al.

Table 1 Composition of Bioglass

\begin{tabular}{|l|l|}
\hline Chemical compound & Content (\%) \\
\hline Silicon dioxide & 45 \\
\hline Sodium oxide & 24.5 \\
\hline Calcium oxide & 24.5 \\
\hline Phosphorus pentoxide & 6 \\
\hline
\end{tabular}

firm bond with bone that could only be detached on breaking the bone. ${ }^{2}$

The University of Florida used "Bioglass" as trade name for the original $45 \mathrm{~S} 5$ composition. Thus, the term Bioglass is used to refer to the 45S5 composition and is not a general term for bioactive glass. ${ }^{3}$

\section{Composition}

Besides above content, it may also contain some of biocompatible and bioactive minerals like:

1. Fluorapatite

2. Wollastonite

3. Diopside

4. Tricalcium phosphate $(\text { - Table } \mathbf{1})^{4}$

Network modifiers, namely $\mathrm{CaO}, \mathrm{Na}_{2} \mathrm{O}$, and $\mathrm{P}_{2} \mathrm{O}_{5}$, are generally used. ${ }^{5}$ However, both $\mathrm{CaO}$ and $\mathrm{Na}_{2} \mathrm{O}$ may be replaced with magnesium oxide and potassium oxide, which promote apatite crystal formation. To alter the surface reactions and melting properties, aluminum oxide and barium oxide may be added. ${ }^{6}$ Ions may be added for modifying bioactivity and antimicrobial properties, viz. silicon ions, phosphorus ions, strontium ions, silver ions, zinc ions, and fluoride ions. ${ }^{7}$ More acid-resistant fluorapatite formation is initiated, rather than hydroxyapatite. Augmented remineralization of dentin and reduced possibility of dentin-matrix degradation is initiated by fluoride coupled with Bioglass. These attributes make fluoride vitally important in dental applications of Bioglass. ${ }^{8}$

There are two variants of Bioglass available, type A and type B. The type A is alkali-free Bioglass, especially sodium, with a composition of $70 \%$ diopside, $10 \%$ fluorapatite, and $20 \%$ tricalcium phosphate, while the type B variant is bioinert with silica content greater than $60 \%$ by weight. ${ }^{9}$

\section{Method of Preparation}

Conventionally, glasses were prepared using melt quenching above $1,300^{\circ} \mathrm{C}$. Nevertheless, this method had a few drawbacks such as:

- Bioactivity of the substance is reduced owing to high sintering temperature.

- Ineffective to fabricate porous scaffolds. ${ }^{10}$

Also, heat treatment of silicon-containing Bioglass results in release of stress from glass, thereby affecting the mechanical properties. ${ }^{11}$

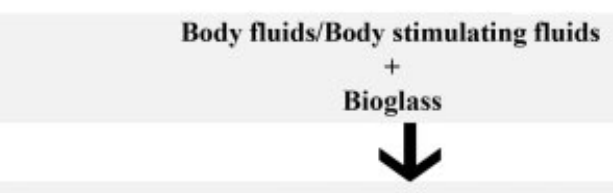

Bioglass undergoes ionic dissolution \& glass disintegrates via exchange of $\mathrm{H}+$ in solution and $\mathrm{Na}+, \mathrm{Ca}++$ from glass network

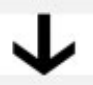

Results to form Si-O-H

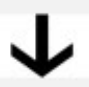

Forms orthosilicate acid \& $\mathrm{Si}(\mathrm{OH}) 4$ on surface on surface in form of negatively charged gel

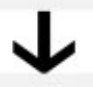

Gel layer functions as matrix

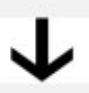

Precipitation and mineralization

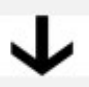

New bone growth tissue occurs

Fig. 1 Schematic representation of mechanism of action of Bioglass.

Another method of preparation of Bioglass used since 1970s is "sol-gel technique."1 This process involves hydrolysis and condensation followed by low-temperature heat treatment. This approach has encouraged manufacturers to produce variety of glasses, differing in content and structure, viz. fibers, coatings, scaffolds, and nanoparticles. It has elevated porosity, apatite-formation ability, and more surface area in contrast to melt quenching, which imparts higher

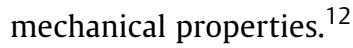

\section{Mechanism of Action}

When Bioglass is placed at the defect site, body fluids begin to hydrate glass surface thereby initiating conversion reaction; soon, thin layer of hydroxyapatite crystal is formed over glass surface that thickens over time thereby inducing other body cells to take actions as per location followed by mineralization of the matrix (-Fig. 1). ${ }^{13}$

\section{Properties of Bioglass}

Bioglass is biocompatible, nontoxic, and chemically stable in biological environment. It has antimicrobial property as well, since it elevates the $\mathrm{pH}$ and osmolarity locally, thereby creating unfavorable environment for bacterial growth. ${ }^{14,15}$

Bioglass differs highly from conventional glass in its dissolution. Bioglass requires a particular dissolution for 
its activation, which is accomplished by addition of network modifiers like $\mathrm{CaO}$ or $\mathrm{Na}_{2} \mathrm{O}$, which makes both the surface and silica reactive. ${ }^{14}$

Alkali-free Bioglass coupled with zinc oxide and strontium oxide imparts antimicrobial property against Staphylococcus aureus and Escherichia coli. These features make Bioglass a classic bone alternative in remedy for osteomyelitis, periimplant infection, sinus augmentation, and repairing orbital floor flaws. ${ }^{15,16}$

As Bioglass can be incorporated into hydrophilic and hydrophobic conditions, it may be used along with dental implants as coating. ${ }^{17}$ Also, particle size influences the antimicrobial properties; smaller-sized particles provide larger surface area, thus increasing the antimicrobial effects. ${ }^{18}$

\section{Advantages and Disadvantages of Bioglass}

The chief advantage of Bioglass, which makes it a noteworthy innovation, is the high surface speed reaction that facilitates forming of rapid networks to the tissues. Its bioactive nature, broad-spectrum antimicrobial properties, and biocompatibility are few other advantages. However, every material has some disadvantages; the main disadvantage of Bioglass is its low mechanical strength. ${ }^{19}$

\section{Clinical Application}

As a result of its broad-spectrum antimicrobial property and bioactive property, Bioglass has been a topic of keen interest for researchers. Bioglass has made its various clinical implementations in fields of dentistry, spinal implants, tissue engineering, and various other medical aspects. ${ }^{17,20}$ In the discipline of dentistry, it was initially used in practice as bone replacements in periodontal regeneration, dentoalveolar and maxillofacial reconstruction, and implants. ${ }^{21}$ Other contributions of Bioglass in dentistry include its use as restorative material, in intracanal medicament used for pulp capping, as dental adhesives, for

\section{CLINICAL APPLICATIONS}

\footnotetext{
$\rightarrow$ IN ORAL AND MAXILlOFACIAL SURGERY $\rightarrow$ AS RESTORATIVE MATERIAL $\rightarrow$ AS INTRACANAL MEDICAMENT $\rightarrow$ TO TREAT DENTIN HYPERSENSITIVITY $\rightarrow$ AS DENTAL ADHESIVES $\rightarrow$ IN PERIODONTICS $\rightarrow$ IN IMPLANT DENTISTRY $\rightarrow$ FOR ENAMEL REMINERILZATION
}

Fig. 2 Clinical applications of Bioglass in dentistry. enamel regeneration, and to treat dental hypersensitivity and air abrasion (-Fig. 2).

\section{Bioglass in Oral Maxillofacial Surgery}

Bioglass induces superiority in quality and magnitude of bone generation and at a faster rate in contrast to calcium phosphate-based compound. $^{22}$

Biogran (Biomet 3i, Palm Beach Gardens, Florida, United States) is commercially available for maxillofacial applications. It is widely used for repair or rehabilitation of maxillofacial faults. Biogran (Biomet 3i, Palm Beach Gardens, Florida, United States) differs from PerioGlass (NovaBone Products LLC, Alachua, Florida, United States) in their particle size. $^{23}$

NovaBone (NovaBone Products LLC) is commercially available, which may be employed to make putty using blood from site of defect. ${ }^{24}$

Strontium oxide containing Bioglass has demonstrated to reduce bone resorption. ${ }^{25}$ The alkali-free Bioglass is more biocompatible, resorbs bone at a slow rate, and has higher osteoconductive property, which makes it more suitable for dental and oral maxillofacial usages. ${ }^{26}$

\section{Bioglass As Restorative Material}

Almost all of the restorative materials available are biomimetic but not bioactive. Also, they undergo some degree of polymerization contraction leading to formation of microgap, thus leading to microleakage, which affects the mechanical properties of both tooth and the restoration. This microgap is often beyond the reach of routine dental hygiene practice, thereby creating favorable environment for microorganisms' growth, thus leading to secondary caries and restoration failures. ${ }^{27}$

Bioglass as restorative material induces remineralization, as it seals marginal interfaces with hydroxyapatite crystal precipitates. ${ }^{28}$ Fluoride-containing Bioglass causes remineralization of dentin. It also reduces enzyme-mediated collagen network degradation of dentin. Resin composite with Bioglass filler exhibits antimicrobial and bioactive properties, which prevent secondary caries. ${ }^{29}$

Resin-modified glass ionomer cement (GIC)-containing bioactive glass has higher remineralization property. Also, it exhibits active antimicrobial property against Candida albicans and Streptococcus mutants. ${ }^{30}$ This is the potential reason behind the effectiveness of resin-modified GIC-containing Bioglass in prevention of secondary caries. ${ }^{31}$ However, integration of Bioglass with resin-modified GIC weakens its strength and mechanical properties thereby limiting its uses as liners and for cavities where occlusal forces are not so strong. ${ }^{32}$

\section{Bioglass as Intracanal Medicament}

The main interfering determinants in the periapical repair process are bacteria and its derivatives as they play a crucial role in periradicular diseases development and its 
advancement. ${ }^{33,34}$ Disinfection of the complicated root canal structure is vital as C. albicans and Enterococcus faecalis are the enduring root canal microorganisms that lead to root canal treatment failure. This disinfection also imparts longevity to the treatment. ${ }^{35}$ Suitable intracanal medicament in between treatment sessions provide effectives antimicrobial effect. A broad-spectrum antimicrobial property is the ideal requirement for an intracanal medicament, since it is more suitable with periapical tissue and induces hard tissue repair, also reducing inflammation at the same time. ${ }^{36,37}$

As discussed earlier, Bioglass has antimicrobial and antiinflammatory effects along with osteoconductive properties that aid in repair of bone faults. ${ }^{38}$ The broad-spectrum antimicrobial effects account for the use of Bioglass as intracanal medicament. 39,40

Recent researches show that Bioglass has higher antimicrobial effect in contrast to calcium hydroxide, which is due to the fact that calcium hydroxide is affected by buffering actions of dentin, whereas Bioglass is less responsive to the same. ${ }^{41}$

Clinical outcome: A recent research was conducted to study the effectiveness of chlorhexidine gluconate- $1 \%$ gel and bioactive glass S53P4 as intracanal medicaments. Method used in the study was polymerase chain reaction. The result showed that both medicaments caused a considerable reduction in amount of bacterial growth. Bioglass S53P4 caused much more reduction than chlorhexidine gluconate- $1 \%$ gel. Hence, to conclude, we can say that Bioglass S53P4 has better antibacterial property as compared with chlorhexidine gluconate- $1 \%$ gel. ${ }^{42}$

\section{To Treat Dentin Hypersensitivity}

An intense and momentary dental ache due to a physical, chemical, osmotic, evaporative, or thermal cause is termed as dentin hypersensitivity. Most accepted dentin hypersensitivity theory is the hydrodynamic theory. ${ }^{43}$ Commercially available Sensodyne (GlaxoSmithKline) toothpaste has Novamin to deliver relief by blocking the dentinal tubules and precipitating hydroxyapatite crystal. The use of Bioglass instead of silica in toothpaste provides resilience against $\mathrm{pH}$ rinse and helps cleaning off the blocked tubules. Recent experimental studies show that Bioglass biosilicate dispersion in distilled water provides remedy for a follow-up period of 6 months against dentin hypersensitivity. ${ }^{44}$ The major advantage of using Bioglass in dentifrices is that it induces hydroxyapatite formation, which in turn has following advantages:

- It induces remineralization.

- It is used for treatment of dentine hypersensitivity.

- Hydroxyapatite can bind to microorganisms by interacting with the bacterial adhesin thus agglutinating the microorganism. ${ }^{45}$

Fluoride Bioglass may be recommended for treatment of dentin hypersensitivity. It can be used daily by individuals with a compromised periodontal status and individuals with a compromised enamel surface. ${ }^{46}$

\section{Dental Adhesives}

Dental adhesives make adherence, or bonding, of a compound or material, like composites used in dentistry or orthodontic brackets, to natural tooth tissue achievable. The adhesive functions to link two substances. ${ }^{26}$

With use of orthodontic brackets, cases of white spot lesion are common. A favorable condition for microbial flora growth is initiated, since the orthodontic bracket adheres to the tooth surface. Prevention of white spot lesion incurs additional costs as regular tooth brushing and use of fluoride dentifrices, mouthwash, or varnishes become vital. A high degree of patient cooperation is necessity to achieve adequate results. A key interest of the researchers in this filed is to improvise fluoride-releasing sealants, primers, and adhesives to achieve continuous fluoride release throughout orthodontic treatment, so as to prevent occurring of white spot lesions caused due to use of orthodontic brackets. However, addition of fluoride decreases the mechanical properties of the resin-based adhesives, though fluoride release is reduced or is exhausted over time. ${ }^{26}$ Bioglass has a bonding system that reduces micropermeability by inducing remineralization of mineral-deficient areas while showing increase in modulus of elasticity at same time. This property makes Bioglass suitable as dental adhesives. A bioactive glass ceramic is Biosilicate, which when applied before application enhances the bond strength system in both mineralized and unmineralized dentins. ${ }^{47}$

\section{In Periodontics}

Periodontitis is chronic inflammation of the periodontium, which is marked by formation of pockets in gingiva, resorption of alveolar bone, loss of attachment, and thus leading to loss of tooth structure if not treated. ${ }^{48}$

Bioglass in form of PerioGlass (NovaBone Products LLC, Alachua, Florida, United States) is widely used to repair periodontal defects as it is an excellent grafting material. It also found its uses in periodontal surgical practices to activate bone regeneration, to be specific, in interproximal bone faults; this effectiveness is a result of its hemostatic effect on trabecular bone. ${ }^{49}$

\section{In Implant Dentistry}

Dental implants are artificial screw-shaped tools that are inserted into alveolar socket or periosteum, to hold replacement or bridge. Dental implant finds its uses in prosthodontic constructions to improve its action and aesthetics. ${ }^{50}$ Uninterrupted contact between the implant surface and bone tissue is vital to accomplish adequate retention in bone, or osseointegration. ${ }^{51}$ Titanium-based alloys are extensively employed materials for dental implants; these are biocompatible and osteoconductive materials, but are bioinert. This bioinert nature is overcome by addition of Bioglass. Titanium-based alloy implant, along with Bioglass, provides active bonding and antimicrobial properties, thus reducing overall treatment time. $^{52}$ 
Table 2 Clinical outcome of study conducted on hydroxyapatite-, Bioglass-, and Ti6Al4V-coated implants

\begin{tabular}{|l|l|l|l|}
\hline & $\begin{array}{l}\text { Hydroxyapatite } \\
\text { coated }\end{array}$ & $\begin{array}{l}\text { Bioglass } \\
\text { coated }\end{array}$ & $\begin{array}{l}\text { Ti6Al4V } \\
\text { coated }\end{array}$ \\
\hline Total & 41 & 45 & 40 \\
\hline $\begin{array}{l}\text { Failed prosthetic } \\
\text { attachment }\end{array}$ & 23 & 21 & 20 \\
\hline
\end{tabular}

Clinical outcome: A study was undertaken to examine the clinical outcomes of hydroxyapatite-, Bioglass-, and Ti6Al4Vcoated dental implants ( $\mathbf{-}$ Table $\mathbf{2}$ ).

Abnormal motility in perpendicular direction was observed with pus formation; along with this, resorption of almost the entire area of hydroxyapatite coating was observed in hydroxyapatite-coated failure implants. However, Bioglasscoated implants were devoid of any such complications, as horizontal mobility and partial resorption of coating were observed with failed Bioglass-coated implant. ${ }^{53}$

\section{Enamel Remineralization}

Primary carious lesions that have not cavitated, for example white spot lesion, may be prevented from further spreading and remineralization. Through routine plaque removal and fluoride deposition, operative procedures may be avoided. Fluoride has extensive applications in toothpaste, varnishes, and mouth rinse due to its anticariogenic property, and also because it enhances remineralization. ${ }^{54}$

Fluoride doped with Bioglass exhibits potential usage in dental utilization, for example, as dentifrices and restorative materials. ${ }^{55}$ A Bioglass coupled with fluoride and increased phosphate content is commercially available as BiominF, which results in the formation of fluorapatite, in contrast to calcium fluorite. The significantly higher phosphate content provides a source for vital ions of fluorapatite. ${ }^{56}$

\section{Conclusion}

Hence, in conclusion we can say that Bioglass is a recent innovation that is not only beneficial in various aspects of dentistry but also in orthopaedics and spinal implants. The properties that make Bioglass a diverse material to be used in dentistry are:

- It is bioactive.

- It is biocompatible.

- It has a broad-spectrum antimicrobial property.

Despite Bioglass having a higher bone regeneration capacity than bioceramics, it lags behind other bioceramics in terms of commercial success, which may be due to its low strength. Bioglass may have not yet reached its utmost usage, but research activity is growing.

Note

We as authors have investigated:
- The ability of the nanoparticulate glass and $\beta$-tricalcium phosphate to form crystalline apatite layer on the surface of material (that is, in vitro mineralization).

- The antimicrobial efficacy of bioactive glass, tricalcium phosphate, and calcium hydroxide material.

- The preparation and characterization of nanometric bioactive glass and $\beta$-tricalcium phosphate.

\section{Funding}

Nil.

Conflict of Interest

Nil.

\section{References}

1 Hench LL. The story of bioglass. J Mater Sci Mater Med 2006;17 (11):967-978

2 Ferreira MM, Brito AF, Brazete D, et al; Experimental Study in Rats. Doping $\beta$-TCP as a strategy for enhancing the regenerative potential of composite $\beta$-TCP-alkali-free bioactive glass bone grafts. Materials (Basel) 2018;12(01):4. Doi: 10.3390/ma12010004

3 Hench LL, Splinter RJ, Allen WC, Greenlee TK. Bonding mechanisms at the interface of ceramic prosthetic materials. J Biomed Mater Res Symp 1971;5(06):117-141

4 Skallevold HE, Rokaya D, Khurshid Z, Zafar MS. Bioactive glass applications in dentistry. Int J Mol Sci 2019;20(23):5960. Doi: 10.3390/ijms20235960

5 Rodriguez O, Alhalawani A, Arshad S, Towler MR. Rapidly-dissolving silver-containing bioactive glasses for cariostatic applications. J Funct Biomater 2018;9(02):28. Doi: 10.3390/jfb9020028

6 Jones J, Gentleman E, Polak J. Bioactive glass scaffolds for bone regeneration. Elements. 2007;3:393-399

7 Hoppe A, Jokic B, Janackovic D, et al. Cobalt-releasing 1393 bioactive glass-derived scaffolds for bone tissue engineering applications. ACS Appl Mater Interfaces 2014;6(04):2865-2877

8 Groh D, Döhler F, Brauer DS. Bioactive glasses with improved processing. Part 1 . Thermal properties, ion release and apatite formation. Acta Biomater 2014;10(10):4465-4473

9 El-Meliegy E, Noort R. Glasses and Glass Ceramics for Medical Applications. New York, NY: Springer; 2012

10 Chen QZ, Xu JL, Yu LG, Fang XY, Khor KA. Spark plasma sintering of sol-gel derived 45S5 Bioglass ${ }^{\circledR}$-ceramics: mechanical properties and biocompatibility evaluation. Mater Sci Eng C 2012;32:494-502

11 Prasad S, Vyas VK, Ershad M, Pyare R. Crystallization and mechanical properties of (45S5-HA) biocomposite for biomedical implantation. Ceram Silik 2017;61:378-384

12 Wu C, Fan W, Gelinsky M, et al. Bioactive SrO-SiO2 glass with wellordered mesopores: characterization, physiochemistry and biological properties. Acta Biomater 2011;7(04):1797-1806

13 Jones JR. Review of bioactive glass: from Hench to hybrids. Acta Biomater 2013;9(01):4457-4486

14 Hill RG, Brauer DS. Predicting the bioactivity of glasses using the network connectivity or split network models. J Non-Cryst Solids 2011;357:3884-3887

15 Stoor P, Söderling E, Salonen JI. Antibacterial effects of a bioactive glass paste on oral microorganisms. Acta Odontol Scand 1998;56 (03):161-165

16 Lindfors NC, Hyvönen P, Nyyssönen M, et al. Bioactive glass S53P4 as bone graft substitute in treatment of osteomyelitis. Bone 2010; 47(02):212-218

17 Galarraga-Vinueza ME, Mesquita-Guimarães J, Magini RS, Souza JC, Fredel MC, Boccaccini AR. Anti-biofilm properties of bioactive glasses embedding organic active compounds. J Biomed Mater Res A 2017;105(02):672-679 
18 Salonen JI, Arjasmaa M, Tuominen U, Behbehani MJ, Zaatar E. Bioactive glass in dentistry. J Minim Interv Dent 2009;2: 208-2018

19 Sarin S, Rekhi A. Bioactive glass: a potential next generation biomaterial. SRM J Res Dent Sci 2016;7:27-32

20 Lanza R, Langer R, Vacanti J. Principles of Tissue Engineering. 3rd ed. Cambridge, MA: Academic Press; 2011 ISBN 9780080548845

21 Lovelace TB, Mellonig JT, Meffert RM, Jones AA, Nummikoski PV, Cochran DL. Clinical evaluation of bioactive glass in the treatment of periodontal osseous defects in humans. J Periodontol 1998;69 (09):1027-1035

22 Peltola MJ, Aitasalo KM, Suonpää JT, Yli-Urpo A, Laippala PJ, Forsback AP. Frontal sinus and skull bone defect obliteration with three synthetic bioactive materials. A comparative study. J Biomed Mater Res B Appl Biomater 2003;66(01):364-372

23 Tadjoedin ES, de Lange GL, Lyaruu DM, Kuiper L, Burger EH. High concentrations of bioactive glass material (BioGran) vs. autogenous bone for sinus floor elevation. Clin Oral Implants Res 2002; 13(04):428-436

24 Hench L, Hench JW, Greenspan D. Bioglass: a short history and bibliography. J. Aust. Ceram Soc. 2004;40:1-42

25 Fujikura K, Karpukhina N, Kasuga T, Brauer D, Hill R, Law R. Influence of strontium substitution on structure and crystallisation of Bioglass ${ }^{\circledR}$ 45S5. J Mater Chem 2012;22:7395-7402

26 Skallevold HE, Rokaya D, Khurshid Z, Zafar MS. Bioactive glass applications in dentistry. Int J Mol Sci 2019;20(23):5960. Doi: 10.3390/ijms20235960

27 Pereira-Cenci T, Cenci MS, Fedorowicz Z, Marchesan MA. Antibacterial agents in composite restorations for the prevention of dental caries. Cochrane Database Syst Rev 2009;(03):CD007819. Doi: 10.1002/14651858.CD007819.pub3

28 Profeta AC. Dentine bonding agents comprising calcium-silicates to support proactive dental care: origins, development and future. Dent Mater J 2014;33(04):443-452

29 Tezvergil-Mutluay A, Seseogullari-Dirihan R, Feitosa VP, Cama G, Brauer DS, Sauro S. Effects of composites containing bioactive glasses on demineralized dentin. J Dent Res 2017;96(09): 999-1005

30 Khvostenko D, Mitchell JC, Hilton TJ, Ferracane JL, Kruzic JJ. Mechanical performance of novel bioactive glass containing dental restorative composites. Dent Mater 2013;29(11):1139-1148

31 Yli-Urpo H, Närhi T, Söderling E. Antimicrobial effects of glass ionomer cements containing bioactive glass (S53P4) on oral microorganisms in vitro. Acta Odontol Scand 2003;61(04):241-246

32 Prabhakar AR, Paul M J, Basappa N. Comparative evaluation of the remineralizing effects and surface micro hardness of glass ionomer cements containing bioactive glass (S53P4): an in vitro study. Int J Clin Pediatr Dent 2010;3(02):69-77

33 Siqueira JF Jr, Rôças IN, Souto R, de Uzeda M, Colombo AP. Actinomyces species, streptococci, and Enterococcus faecalis in primary root canal infections. J Endod 2002;28(03):168-172

34 Siqueira JF Jr. Aetiology of root canal treatment failure: why welltreated teeth can fail. Int Endod J 2001;34(01):1-10

35 Krithikadatta J, Indira R, Dorothykalyani AL. Disinfection of dentinal tubules with $2 \%$ chlorhexidine, $2 \%$ metronidazole, bioactive glass when compared with calcium hydroxide as intracanal medicaments. J Endod 2007;33(12):1473-1476

36 Love RM. Enterococcus faecalis-a mechanism for its role in endodontic failure. Int Endod J 2001;34(05):399-405

37 Chong BS, Pitt Ford TR. The role of intracanal medication in root canal treatment. Int Endod J 1992;25(02):97-106

38 Oguntebi BR. Dentine tubule infection and endodontic therapy implications. Int Endod J 1994;27(04):218-222
39 Safavi KE, Spangberg LS, Langeland K. Root canal dentinal tubule disinfection. J Endod 1990;16(05):207-210

40 Thomas MV, Puleo DA, Al-Sabbagh M. Bioactive glass three decades on. J Long Term Eff Med Implants 2005;15(06):585-597

41 Zehnder M, Söderling E, Salonen J, Waltimo T. Preliminary evaluation of bioactive glass S53P4 as an endodontic medication in vitro. J Endod 2004;30(04):220-224

42 Goel A, Sinha A, Khandeparker RV, Mehrotra R, Vashisth P, Garg A. Bioactive glass S53P4 versus chlorhexidine gluconate as intracanal medicament in primary teeth: an in-vivo study using polymerase chain reaction analysis. J Int Oral Health 2015;7 (08):65-69

43 Idon PI, Esan TA, Bamise CT. Oral health-related quality of life in patients presenting with dentine hypersensitivity: a randomized controlled study of treatment effect. Eur J Gen Dent 2017; 6:99-105

44 Tirapelli C, Panzeri H, Lara EH, Soares RG, Peitl O, Zanotto ED. The effect of a novel crystallised bioactive glass-ceramic powder on dentine hypersensitivity: a long-term clinical study. J Oral Rehabil 2011;38(04):253-262

45 Chen L, Al-Bayatee S, Khurshid Z, Shavandi A, Brunton P, Ratnayake J. Hydroxyapatite in oral care products-a review. Materials (Basel) 2021;14(17):4865. Doi: 10.3390/ma14174865

46 Anthoney D, Zahid S, Khalid H, et al. Effectiveness of thymoquinone and fluoridated bioactive glass/nano-oxide contained dentifrices on abrasion and dentine tubules occlusion: an ex vivo study. Eur J Dent 2020;14(01):45-54

47 de Morais RC, Silveira RE, Chinelatti M, Geraldeli S, de Carvalho Panzeri Pires-de-Souza F. Bond strength of adhesive systems to sound and demineralized dentin treated with bioactive glass ceramic suspension. Clin Oral Investig 2018;22(05):1923-1931

48 Hirschfeld L, Wasserman B. A long-term survey of tooth loss in 600 treated periodontal patients. J Periodontol 1978;49(05): 225-237

49 Profeta AC, Prucher GM. Bioactive-glass in periodontal surgery and implant dentistry. Dent Mater J 2015;34(05):559-571

50 Müller F, Wahl G, Fuhr K. Age-related satisfaction with complete dentures, desire for improvement and attitudes to implant treatment. Gerodontology 1994;11(01):7-12

51 Albrektsson T, Brånemark PI, Hansson HA, Lindström J. Osseointegrated titanium implants. Requirements for ensuring a longlasting, direct bone-to-implant anchorage in man. Acta Orthop Scand 1981;52(02):155-170

52 Talreja PS, Gayathri GV, Mehta DS. Treatment of an early failing implant by guided bone regeneration using resorbable collagen membrane and bioactive glass. J Indian Soc Periodontol 2013;17 (01):131-136

53 Mistry S, Roy R, Kundu B, et al. Clinical outcome of hydroxyapatite coated, bioactive glass coated, and machined Ti6Al4V threaded dental implant in human jaws: a short-term comparative study. Implant Dent 2016;25(02):252-260

54 Mendes AC, Restrepo M, Bussaneli D, Zuanon AC. Use of casein amorphous calcium phosphate (CPP-ACP) on white-spot lesions: randomised clinical trial. Oral Health Prev Dent 2018;16(01): 27-31

55 Brauer DS, Karpukhina N, O'Donnell MD, Law RV, Hill RG. Fluoride-containing bioactive glasses: effect of glass design and structure on degradation, $\mathrm{pH}$ and apatite formation in simulated body fluid. Acta Biomater 2010;6(08):3275-3282

56 Farooq I, Majeed A, Alshwaimi E, Almas K. Efficacy of a novel fluoride containing bioactive glass based dentifrice in remineralizing artificially induced demineralization in human enamel. Fluoride 2018;52:447-455 